\title{
UMA NOVA ENFERMAGEM PSIQUIÁTRICA NA UNIVERSIDADE DO BRASIL NOS ANOS 60 DO SÉCULO XX
}

\author{
A New Psychiatric Nursing in the University of \\ Brazil in the $60^{\prime}$ s of the $20^{\text {th }}$ Century \\ Una Nueva Enfermería Psiquiátrica en la Universidad \\ del Brasil en los Años 60 del Siglo 20
}

Maria Angélica de Almeida Peres ${ }^{1}$

leda de Alencar Barreira²

\section{Resumo}

Estudo histórico-social sobre a implantação de um modelo de enfermagem psiquiátrica, pela Escola Ana Nery (EAN), no Instituto de Psiquiatria da Universidade do Brasil (IPUB). 0 marco inicial corresponde à contratação de uma professora da escola como chefe do serviço de enfermagem do IPUB, em 1962, e o marco final, à inclusão das enfermeiras como integrantes da equipe de saúde do IPUB, em 1963. Objetivos: descrever a situação da enfermagem psiquiátrica no IPUB; analisar as estratégias adotadas na reforma da enfermagem; discutir a importância desse saber/poder da enfermagem. Referencial teórico: conceitos de Michel Foucault. Fontes: documentos escritos, depoimentos orais e bibliografia. Resultados: as estratégias utilizadas foram de natureza política, técnica e administrativa; suas condições de possibilidade foram dadas pela acumulação de cargos (docente e assistencial). A consolidação do novo modelo, ampliado para outras escolas, tornou a EAN/IPUB centro de difusão de saber da enfermagem psiquiátrica no Brasil.

Palavras-chave: Enfermagem Psiquiátrica. História da Enfermagem. Ensino.

\begin{abstract}
Historical-social study about the implementation of a model of psychiatric nursing, by the School Ana Nery (EAN), in the Institute of Psychiatry of the University of Brazil (IPUB). The initial landmark corresponds to the contracting of a professor of the school as the leader of the service of nursing of the IPUB, in 1962, and the final landmark to the enclosure of the nurses like members of the team of health of the IPUB, in 1963. Objective: describe the situation of the psychiatric nursing in the IPUB; analyze the strategies adopted in the reform of the nursing; discuss the importance of that know/ power about the nursing. Theoretical reference: concepts of Michel Foucault. Springs: documents writing, oral statements and bibliography. Results: the strategies utilized were of administrative, technical, and political nature; his conditions of possibility were given by the accumulation of charges (educational and assistencial) The consolidation of the new model, extended for other schools, became the EAN/IPUB centers of diffusion of know about the psychiatric nursing in Brazil.
\end{abstract}

Keywords:

Psychiatric nursing. History of the nursing. Teaching.

\section{Resumen}

Estudio histórico- social acerca de la implementación de un modelo de la enfermería psiquiátrica, por la "Escuela Ana Nery" (EAN), en el "Instituto de la Psiquiatría de la Universidad de Brasil” (IPUB). La señal inicial corresponde al contratar de un profesor de la escuela como el líder del servicio de la enfermería del IPUB, en 1962, y la señal final al cerco de las enfermeras como miembros del equipo de la salud del IPUB, en 1963. Objetivos: Describir la situación de la enfermería psiquiátrica en el IPUB; analizar las estrategias adoptadas en la reforma de la enfermería; discutir la importancia de eso saber/poder acerca de la enfermería. Referencia teórica: conceptos de Michel Foucault. Fuentes: documentos escritos, declaraciones orales y bibliografía. Resultados: las estrategias utilizadas fueron de naturaleza política, técnica y administrativa; sus condiciones de posibilidad fueron dadas por la acumulación de cargos (educativo y assistencial) La consolidación del nuevo modelo, prolongado para otras escuelas, volvió la EAN/IPUB centros de difusión de saber acerca de la enfermería psiquiátrica en Brasil.

Palabras clave:

Enfermería psiquiátrica. Historia de la enfermería. Enseñanza.

'Professora Assistente do Departamento de Enfermagem Fundamental da Escola de Enfermagem Anna Nery/UFRJ. Doutoranda em Enfermagem na EEAN/UFRJ. Membro do Núcleo de Pesquisa de História da Enfermagem - Nuphebras. ${ }^{2}$ Doutora em História da Enfermagem. Professora do Quadro Permanente do Programa de Pós-Graduação da EEAN / UFRJ. Membro Fundador do Núcleo de Pesquisa de História da Enfermagem Brasileira - Nuphebras. Pesquisador 1A CNPq. 


\section{INTRODUÇÃO}

0 presente estudo tem como objeto a implantação de um modelo inovador de assistência de enfermagem psiquiátrica, pela Escola Ana Nery (EAN), no Instituto de Psiquiatria da Universidade do Brasil (IPUB), atual Universidade Federal do Rio de Janeiro, no início dos anos de 1960. 0 marco inicial corresponde à contratação da primeira enfermeira diplomada e também professora da EAN, como chefe do serviço de enfermagem do IPUB, em 1962. 0 marco final corresponde à inclusão das enfermeiras na relação nominal de integrantes da equipe de saúde do IPUB, publicada em seu órgão de divulgação oficial, o Jornal Brasileiro de Psiquiatria (JBP), em 1963; tal fato assinala o reconhecimento simbólico do saber da enfermagem psiquiátrica.

Desde sua criação e por mais de duas décadas do século $X X$, não houve estágio em enfermagem psiquiátrica na EAN, que se manteve afastada do hospital psiquiátrico por 27 anos (1923-1950). De acordo com a percepção de professoras da EAN, este espaço era considerado inadequado às alunas, devido a questões morais, sexuais e de segurança física, decorrentes do comportamento do doente mental. Pode-se supor que tal afastamento tenha contribuído também para que as enfermeiras por ela diplomadas evitassem trabalhar em serviços psiquiátricos, reforçando o estigma da doença mental.

A introdução do ensino de enfermagem psiquiátrica no currículo da EAN ocorreu progressivamente, indo desde a ausência (19231925), passando para aulas exclusivamente teóricas, ministradas por médicos (1926-1932), depois seguidas por aulas teóricopráticas em sala de aula (1933-1949), e chegando finalmente ao estágio em hospital psiquiátrico (1950).

0 início das atividades práticas das alunas em Enfermagem Psiquiátrica se deu por força da Lei $775 / 49^{2}$, que tornava obrigatório o estágio em todos os campos assistenciais básicos. A EAN iniciou o estágio de psiquiatria logo em 1950, no Centro Psiquiátrico Nacional, tendo como professora Maria Dolores Lins de Andrade, que, em 1953, viajou para os EUA, para fazer especialização em psiquiatria. Quando esta professora voltou, em 1954, o estágio passou a ser no IPUB, onde a EAN iniciou um projeto pedagógico-assistencial.

Em 1957, diante do afastamento da professora Maria Dolores, que se encontrava nos EUA fazendo especialização em didática, a diretora da Escola, professora Waleska Paixão, designou a professora de enfermagem de saúde pública, Isabel da Cunha Dantas, para assumir a disciplina, em caráter eventual'. Após três anos, diante da impossibilidade, por motivos pessoais, da professora Maria Dolores para reassumir a disciplina, em 1960 a EAN contratou a especialista Teresa de Jesus Sena para assumir efetivamente o ensino da enfermagem psiquiátrica e as atividades pedagógico-assistenciais no IPUB 4 .

No IPUB, até essa época, a assistência de enfermagem era prestada, em sua totalidade, por enfermeiros sem diploma de nível superior e que, portanto, não podiam servir de modelo às alunas e nem estavam preparados para supervisionar a assistência de enfermagem na instituição.

Esta situação desfavorável ao ensino da enfermagem psiquiátrica ocorria na maior parte do mundo. Tanto assim, que a Organização Mundial de Saúde (OMS) organizou um Comitê de Expertos em Enfermagem Psiquiátrica, que se reuniu em Genebra, de 29 de agosto a 3 de setembro de 1955, para discutir a prática e a formação em enfermagem psiquiátrica. Tal comitê era composto por nove membros efetivos e três consultores. Os membros efetivos eram cinco enfermeiras psiquiátricas (representantes dos EUA, da Inglaterra, da Suécia, da Austrália e da União Sul-Africana) e quatro médicos, representantes da Inglaterra, dos Países Baixos, da Tailândia e do Egito. Como consultores, participaram uma enfermeira (dos EUA) e dois médicos (dos EUAe da Austrália). Em seu relatório, - Comitê recomendou que os programas de ensino fossem pautados no processo saúde/doença mental; no estudo das relações humanas, em diferentes grupos sociais, bem como em conhecimentos e técnicas sociais e psicológicas, necessárias à prática cotidiana da enfermagem psiquiátrica. 0 Comitê enfatizou ainda a necessidade de que a aluna desenvolvesse um autoconhecimento que the possibilitasse o desempenho de relações terapêuticas com pacientes em qualquer estágio da doença mental ${ }^{5}$.

0 contexto histórico do estudo é do início da década de 1960, que assinala o fim da gestão presidencial de Juscelino Kubitschek (JK), marcada por uma política nacionaldesenvolvimentista. Seu ambicioso programa de obras públicas teve como destaque a construção da nova capital federal, Braślia, no planalto central do Brasil, inaugurada no dia 21 de abril de $1960^{6}$. Ao deixar de ser a capital federal, a cidade do Rio de Janeiro passou a constituir o Estado da Guanabara, cujo primeiro governador eleito foi Carlos Lacerda (1961-1965), pertencente à União Democrática Nacional (UDN), partido conservador, responsável pela desestabilização do último governo Vargas ${ }^{6}$.

Com a mudança da capital do país para Brasília, muitos serviços federais foram transferidos para a jurisdição do novo Estado da Guanabara, inclusive no campo da psiquiatria. 0 Rio de Janeiro continuou, por cer to tempo, sendo a capital cultural do país e centro de referência no que se refere à psiquiatria. 0 Serviço Nacional de Doenças Mentais (SNDM) continuou a manter no Estado da Guanabara os seguintes órgãos locais: 0 Centro Psiquiátrico Nacional, a Colônia Juliano Moreira, o Manicômio Judiciário e ambulatórios, isolados ou anexos a hospitais psiquiátricos ou a hospitais gerais, como o Miguel Couto e o Pedro Ernesto, ambos da esfera estadual ${ }^{7}$.

Nessa época, ganhava força no Brasil o discurso da "nova psiquiatria", que visava à transformação dos hospitais de doenças mentais em centros de cura e de recuperação. Essa mudança da finalidade da internação determinou uma redistribuição do espaço hospitalar psiquiátrico e a necessidade de que os médicos e demais profissionais se tornassem capazes de realizar a pretendida reforma ${ }^{8}$.

De acordo com Lopes ${ }^{9}$, no final da década de 1950, a ampliação do conceito de processo saúde/doença mental, de modo a abranger tanto os aspectos profiláticos como os terapêuticos, demandava mudanças no preparo e no aperfeiçoamento dos técnicos pelas escolas médicas, de enfermagem, de serviço social e de psicologia, a fim de recrutar trabalhadores para o campo da saúde mental. Além disso, deveriam ser implantados cursos de pós-graduação.

A demanda por um novo tipo de enfermeira psiquiátrica veio ao encontro dos interesses da EAN, uma vez que a 
enfermagem teria a oportunidade de desempenhar novo papel e funções mais adequadas à sua competência. Foi este o sentido da contratação, em 1960, da professora Teresa de Jesus Sena, especialista em enfermagem psiquiátrica nos EUA e que trabalhava então como chefe de enfermagem do Hospital Central do Juqueri, em São Paulo. A ela incumbiria promover a reforma do ensino teórico-prático da disciplina na EAN.

A professora Teresa Sena foi a primeira enfermeira diplomada a ser contratada como chefe de enfermagem do IPUB, o que ocorreu em 1962, e que se constituiu um marco fundamental para a construção e o reconhecimento, naquele contexto, de um saber de enfermagem psiquiátrica especializado, voltado ao ensino e à assistência.

Este estudo tem como objetivos: 1) descrever a situação da enfermagem psiquiátrica no IPUB, no início da década de 60 do século XX; 2) analisar as estratégias adotadas para a reforma da assistência de enfermagem no IPUB; 3) discutir a importância histórica deste novo saber/poder da Enfermagem Psiquiátrica, instituído na UB.

\section{METODOLOGIA}

Trata-se de um estudo de cunho histórico-social, derivado da dissertação de mestrado "Relações Institucionais EAN/ IPUB (1957-1963)". As fontes primárias foram documentos escritos do Centro de Documentação da Escola de Enfermagem Anna Nery (Cedoc/EEAN), entre os quais os históricos das alunas da EAN, no período compreendido entre 1923 e 1963, bem como os depoimentos das ex-professoras de Enfermagem Psiquiátrica da EAN: Maria Dolores Lins de Andrade e Teresa de Jesus Sena, do acervo de História Oral do mesmo. Especificamente para este estudo, foram colhidos depoimentos orais de Teresa de Jesus Sena e Isabel da Cunha Dantas. As fontes secundárias foram constituídas por livros sobre História do Brasil, da Enfermagem e da Psiquiatria no Brasil.

Os depoimentos orais foram concedidos com prévia autorização dos sujeitos, na forma de Consentimento Livre e Esclarecido, segundo a Resolução 196/96, do Conselho Nacional de Saúde ${ }^{10}$, gravados em fitas-cassete e posteriormente incorporados ao acervo de História Oral do Cedoc/EEAN, mediante doação das depoentes. Os textos decorrentes das transcrições das gravações foram analisados e interpretados à luz dos conceitos de saber e de poder disciplinar de Michel Foucault e de instituição total de Erving Goffman. 0 projeto desta pesquisa foi aprovado pelo comitê de ética e pesquisa da EEAN/UFRJ, em 20 de junho de 2007.

\section{A ENFERMAGEM NO IPUB}

0 pessoal de enfermagem do IPUB não tinha uma formação especializada e há anos vinha realizando um trabalho assistencial calcado na psiquiatria tradicional, segundo a qual bastava "excluir, disciplinar, alimentar, lavar, vestir, dar um teto e uma cama (...)"11:64. Também aos médicos interessava manter a velha rotina das enfermarias, de modo a não produzir questionamentos ou demandas ${ }^{12}$.

A parte prejudicada era a clientela, cuja voz era silenciada ${ }^{11: 64}$ por não poder questionar ordens médicas baseadas em um saber reconhecido pela academia.
Assim, uma das maiores dificuldades de implantar um novo modelo assistencial era justamente a acomodação das práticas médicas, pelo menos junto aos doentes internados. Aos olhos de uma enfermeira especialista, estes eram medicados em excesso, 0 que contribuía para que quisessem ficar o dia todo acamados ${ }^{12}$.

A enfermagem era subordinada ao serviço administrativo do hospital; o papel de chefe geral da enfermagem era desempenhado pela atendente responsável pela enfermaria feminina, que, mesmo sem saber ler nem escrever, tinha sua autoridade acatada; o cuidado de enfermagem era pautado na vigilância e na contenção dos doentes, inclusive com a utilização de um quarto forte ${ }^{12}$.

As atendentes lidavam com o medo que tinham dos doentes por meio de barganhas:

As atendentes tinham medo, sobremodo as da noite. Elas iam para o pátio porque não tinham confiança de não serem atacadas pelos pacientes, embora elas tentassem um engajamento com os doentes, mas naquela base de faz isto que eu te dou isso (Teresa Sena).

Receber as alunas e professoras durante o período de estágio curricular era parte da rotina assistencial e era uma situação tolerável, pois não tinha influência direta nas relações de poder estabelecidas entre os funcionários do IPUB. A presença das alunas da EAN, de certo modo, até era considerada conveniente para as atendentes, por diminuir sua carga de trabalho.

De outro modo, a presença das alunas da EAN como estagiárias no IPUB representava um inconveniente para o pessoal de enfermagem, que evitava proporcionar qualquer autonomia aos doentes, de modo a não incentivar demandas de sua parte. Assim, havia um conflito de interesses entre 0 pessoal de enfermagem e as alunas:

[...] os atendentes não queriam que a gente fizesse alguma coisa que pudesse adiantar a iniciativa do paciente, por exemplo, ensinar a contar dinheiro, ensinar a ler ou coisa assim (Teresa Sena).

Os avanços rumo à reforma da enfermagem do IPUB foram liderados pela EAN, apoiados pelo diretor do IPUB, Prof. José Leme Lopes, o que contribuiu para a aceitação e o reconhecimento da enfermagem especializada, que lá chegava na figura da professora Teresa Sena.

0 diretor Leme Lopes apresentou a professora aos profissionais do IPUB em sessão solene do Centro de Estudos, proclamando sua autoridade como nova chefe de enfermagem e confirmando sua autorização para que ela promovesse mudanças no espaço mais delicado do hospital: as unidades de internação, onde as relações da enfermagem com os médicos se caracterizavam pela subalternidade e onde a própria equipe de enfermagem resistia a qualquer modificação $0^{12}$. Essa atitude do diretor do IPUB foi estratégica para a implantação de uma nova proposta assistencial, uma vez que as relações de poder, explícitas no espaço asilar, têm sempre como "comissão de frente" a enfermeira e a enfermagem 11:124.

A inserção de uma enfermeira especialista, professora da EAN, na equipe de enfermagem do IPUB, ensejou a introdução de um saber, eficaz às novas propostas assistenciais, desejadas por ambas as instituições. No entanto, a pessoa escolhida para 
proceder às mudanças pretendidas era um elemento estranho às duas instituições (o IPUB e a EAN): a professora Teresa Sena, nordestina, formada na Escola de Enfermagem da Universidade Federal da Bahia, vinda de São Paulo e recémchegada dos EUA. Este fato, se por um lado lhe dava maior liberdade de ação, já que não seria entravada por sentimentos de pertença e solidariedade aos grupos lá estabelecidos, por outro lado, provocava sentimentos manifestos de rejeição.

\section{AS ESTRATÉGIAS ADOTADAS PARA A REFORMA DA ASSISTÊNCIA DE ENFERMAGEM NO IPUB}

Para adequar o IPUB à "nova psiquiatria", havia a necessidade de mudar a prática da enfermagem, em direção a um novo modelo assistencial, condizente com os novos conceitos de saúde mental. Tal reformulação exigia uma enfermagem dinâmica, que pudesse estimular os pacientes. $A$ vivência da professora Teresa Sena nos hospitais psiquiátricos americanos havia lhe ensinado que, para ser enfermeira psiquiátrica, o profissional deveria saber "lidar com emoções, avaliar comportamentos humanos e planejar cuidados adequados a cada situação"13:352

Graças ao seu domínio do saber da enfermagem psiquiátrica, Teresa Sena lentamente foi impondo seu conhecimento de enfermagem junto aos médicos do IPUB. Ela nos conta que os médicos assistentes, em sua maioria, alunos do curso de especialização, foram os primeiros a estabelecer uma aproximação com a nova chefe de enfermagem, buscando apoio em seu conhecimento da situação dos doentes ${ }^{12}$.

Os professores médicos, por não assistirem doentes na enfermaria, tinham menos contato com a enfermagem e representavam um obstáculo maior. Existiam ainda as diferenças de status profissional e de gênero, que marcavam uma distância social entre esses grupos. Contudo, graças ao apoio do prof. Leme Lopes, reforçado pela eventual presença no IPUB da então diretora da EAN, profa . Waleska Paixão, bem acolhida pelo diretor da instituição, foi possível fazer com que a equipe médica viesse a aceitar as novas propostas ${ }^{12}$.

A professora Teresa Sena passou a ministrar às alunas de enfermagem as aulas teóricas de psiquiatria, no lugar dos professores médicos. Para suprir a falta de enfermeiros na instituição, ex-alunas da EAN foram contratadas pelo IPUB, e enfermeiras do quadro da EAN foram cedidas para auxiliar o trabalho de reforma da assistência. Foi colocada uma enfermeira em cada plantão (diurno e noturno), para supervisionar e orientar o trabalho dos atendentes, dando início à construção de um novo modelo de enfermagem psiquiátrica no espaço interno do IPUB. Nesta nova fase, as primeiras enfermeiras contratadas para o IPUB foram treinadas pela professora de psiquiatria. 0 fato de que elas apresentassem um saber elaborado resultava em conflitos com os médicos residentes, que estavam começando o seu aprendizado na prática da especialidade ${ }^{12}$.

0 novo modelo de enfermagem psiquiátrica introduzido no IPUB, mesmo não sendo qualificado por sua cientificidade, possuía "a positividade do reconhecimento do saber efetivo, que não está investido apenas nas demonstrações lógicas e teóricas, mas também nas reflexões, nas narrativas, nos regulamentos institucionais e nas decisões políticas" ${ }^{16}$. Assim, ainda que a partir de um saber dominado, o "novo" serviço de enfermagem do IPUB representava, mesmo que implicitamente, "uma crítica contra a instância teórica unitária do saber médico"16:170.

Inicialmente, enquanto atuava apenas como professora da EAN, a resistência à presença da nova enfermeira era velada; no entanto, diante da possibilidade de sua nomeação como chefe de enfermagem do IPUB, o pessoal de enfermagem se preparou para resistir à sua inserção naquele espaço:

\section{[...] eles criaram problemas, eles fizeram pressão pra eu não ser admitida enfermeira chefe (Teresa Sena).}

A nova chefe usou como estratégia uma lenta ocupação dos espaços. Procurou não impor de uma só vez o saber, a hierarquia e o poder da enfermeira "ananéri". Por isso, não vestiu logo seu uniforme e procurou substituir as ordens pelo exemplo vivo de trabalho, prestando cuidados diretos de enfermagem aos pacientes, cuidando do ambiente e introduzindo a jardinagem como terapia ${ }^{14}$. A cada mudança implantada no serviço, havia uma reação contrária do pessoal de enfermagem, o qual percebeu a abertura do quarto-forte como

um perigo, uma coisa terrível, que não estava no tempo ainda, não tinha pessoal suficiente e o pessoal que tinha era todo leigo. Aí, várias noites eu ía pro Instituto e ficava de plantão, para os doentes poderem dormir com o quarto aberto [...](Teresa Sena).

0 novo modelo assistencial que se introduzia comportava outras formas de tratamento, pautadas no relacionamento, incluindo a escuta do sujeito, o respeito aos seus desejos e necessidades, tornando-o mais próximo da sua condição de cidadão. A proposta investia em um trabalho assistencial psiquiátrico coeso junto ao pessoal de enfermagem. A utilização das idéias da nova psiquiatria dentro do IPUB influenciou mudanças na prática profissional de outros membros da equipe de saúde, como foi o caso da nutricionista:

\section{[...] ninguém comia no prato, nem mesmo com colher \\ [...] eu fui conversar com a nutricionista e disse que, se ela permitisse que os pacientes comessem na bandeja, utilizando talher, eu assistia (Teresa Sena).}

A instauração de um controle, que não estava pautado na submissão a ordens não desejadas, nem a um poder punitivo e opressivo, foi tolerada e enfim aceita pela enfermagem, permitindo uma mudança progressiva no trabalho de "vigilânciaassistência", até então exercido. A consolidação de uma incontestável autoridade da nova chefe da enfermagem foi conquistada e mantida pelo exemplo da autodisciplina:

Todo dia às sete horas da manhã eu estava lá, esperando as alunas para ensinar; à tarde eu fazia tudo pela administração do Instituto e pela enfermaria. Fomos melhorando assim, aos poucos, e eu fiquei lá dezoito anos (Teresa Sena).

A atuação das novas enfermeiras também se pautava no efeito pedagógico do exemplo, no qual elas executavam tarefas 
inicialmente atribuídas aos atendentes como uma forma de impor seu modo de fazer sem que houvesse um confronto explícito entre práticas consideradas boas e ruins. Este tipo de atuação das enfermeiras consistia em uma técnica de poder disciplinar. Para uma classe se tornar dominante, para que ela assegure sua dominação e para que esta dominação se reproduza, são necessárias táticas eficazes, sistemáticas, que funcionem no interior de grandes estratégias, assegurando essa dominação ${ }^{15}$.

0 novo discurso da enfermeira psiquiátrica estabeleceu uma nova relação de poder no espaço do Instituto: as enfermeiras passaram a disciplinar os doentes, e o pessoal de enfermagem era agora subordinado à chefia de enfermagem.

A formação de base psicanalítica de Teresa Sena foi um recurso fundamental para facilitar as relações aluna/professora e aluna/doente mental, além das relações da equipe de enfermagem e, mais amplamente, da equipe de saúde. Sobre a formação da enfermeira psiquiátrica, ela escreveu que, para ser um bom profissional, é indispensável saber trabalhar bem, sem desperdício constante de emoções e que a professora deve ensinar à aluna a mobilizar reservas potenciais, que ajudariam na "introjeção e conscientização do adestramento especial"13:354.

\section{O NOVO SABER/ PODER DA ENFERMAGEM PSIQUIÁTRICA}

A escassez de enfermeiras devidamente preparadas em enfermagem psiquiátrica foi discutida no III Congresso Nacional de Enfermagem (1950), no qual surgiu a recomendação para que as escolas que não possuíssem campo ou pessoal adequado para o ensino de enfermagem psiquiátrica enviassem suas alunas para as escolas que pudessem oferecer tal estágio em regime de filiação $0^{17: 218}$, o que consistia em acolher alunas de outras escolas para estágio. Esta recomendação foi repetida no Congresso seguinte em 1951, considerando que era grande a dificuldade encontrada pelas escolas de enfermagem em obter campos clínicos para realizar os estágios estipulados pelo decreto $\mathrm{n}^{0} 27.426$ de 14/11/1949 ${ }^{18}$.

As relações entre a EAN e o IPUB se tornaram cada vez mais estreitas, devido ao reconhecimento da excelência do novo serviço de enfermagem do IPUB, inclusive por outras escolas de enfermagem brasileiras, no início dos anos de 1960.

Diante da necessidade de reformulação do ensino da enfermagem psiquiátrica, e das novas exigências legais, e à luz das novas tendências da especialidade, várias escolas solicitaram filiação à EAN e essa demanda projetou a Escola e o Instituto como instituições de referência no ensino da enfermagem psiquiátrica.

As primeiras escolas a pedir filiação à EAN, no ano de 1961, foram: a Escola Luiza de Marillac, da Pontifícia Universidade Católica, a Escola Alfredo Pinto, do Ministério da Saúde, e a Escola Wenceslau Brás, de Itajubá-MG ${ }^{19}$. No entanto, o aumento do número de filiações terminou por representar uma sobrecarga de trabalho. Além de as alunas chegarem à EAN sem os esperados conhecimentos básicos sobre psiquiatria, o que fazia com que o tempo do estágio tivesse que ser reduzido ${ }^{20}$, a falta de professoras preparadas para o ensino da enfermagem psiquiátrica deixava a cargo de Teresa Sena todas as alunas:
Nunca faltava aluno para a EAN, todas as Escolas de Enfermagem do Rio de Janeiro fizeram estágio de psiquiatria comigo (Teresa Sena).

Ademais, com o intuito de melhorar o ensino da disciplina, a EAN concedeu estágio não somente às alunas, mas também às professoras de enfermagem psiquiátrica de outras escolas ${ }^{21}$. Não obstante, essas medidas foram decisivas para dar início à difusão de um novo modelo de ensino-assistência de enfermagem psiquiátrica, que se opunha ao modelo manicomial. E isto porque, segundo Miranda ${ }^{11}$, o método pelo qual as professoras aprendem a enfermagem psiquiátrica, bem como suas experiências acumuladas na área, pode determinar como será a sua adaptação à prática, onde o subjetivo é um elemento essencial para estabelecer uma relação terapêutica com o doente mental. As professoras de enfermagem psiquiátrica devem apresentar uma eficácia orientadora e prática, que influencie diretamente na qualidade da assistência.

Deste modo, o esquema de filiação foi aos poucos ampliando o modelo teórico-prático de Enfermagem Psiquiátrica do IPUB, onde professoras e alunas de diversas escolas faziam seu aprendizado. 0 processo de ensino-aprendizagem das escolas de enfermagem possibilitou a ocorrência de discussões teóricas diferenciadas, impulsionando o desenvolvimento do discurso da enfermagem psiquiátrica, inaugurado pela professora da EAN.

0 projeto de enfermagem psiquiátrica de Teresa Sena estava à frente do que a equipe do IPUB inicialmente poderia perceber. Quando foram introduzidas enfermeiras nas equipes do dia e da noite, já com uma nova visão, foi que pôde surgir um novo modelo de assistência de enfermagem psiquiátrica: "0 grupo de trabalho estava preparado para atingir o doente. E, não fossem os remanescentes da 'era passada', (ainda cerca de dez atendentes), sem possibilidade de educação em serviço, já poderíamos nos considerar autoras de uma enfermagem terapêutica, consciente e dinâmica"13:356.

Dessa forma, temos o que Foucault ${ }^{16: 209}$ chamou de limiar de positividades, ou seja, o momento do aparecimento de uma nova formação discursiva, que então se individualiza e ganha autonomia, podendo ser uma formação totalmente nova ou a transformação de uma formação anteriormente existente.

A opção da nova chefe de enfermagem, de lançar mão dos aspectos produtivos do poder a fez ser aceita pela equipe, produzindo junto com a mesma, ainda que lentamente, um novo discurso. Esta estratégia silenciosa surtiu efeito e deu os resultados por ela esperados ${ }^{12}$. Trata-se então de considerar o poder como "uma rede produtiva, que atravessa todo o corpo social, muito mais do que uma instância negativa, que tem por função reprimir"15:8.

A nova concepção de assistência de enfermagem psiquiátrica correspondeu a uma ruptura com uma prática baseada no princípio da coerção. Assim, a maior dificuldade foi conseguir que a equipe de enfermagem se desligasse da estrutura manicomial excludente, até então em vigor, como ela mesma interpretou: "Custa-nos instituir algo, até uma simples mudança no antiquado regime de trabalho; mesmo quando isso implica em melhoria para eles, é motivo para ansiedade e temor"13:353.

Essas atitudes referentes à teoria e à prática da assistência de enfermagem psiquiátrica no IPUB fizeram parte das estratégias da EAN para se colocar no espaço acadêmico como 
representante de um saber inovador, coerente com a "nova psiquiatria". Tal posição colocou suas alunas diante de um espaço para as atividades práticas, adequado às exigências legais. Por outro lado, a inserção de ex-alunas da EAN como enfermeiras do IPUB foi importante para a implantação do novo modelo de enfermagem.

0 novo perfil proposto para a Enfermagem Psiquiátrica não significava, contudo, uma total mudança na prática assistencial, construída ao longo dos anos. No entanto, nela os aspectos repressivos passaram a ser exercidos de forma mais sutil e com vistas ao tratamento dos doentes mentais. Esse novo discurso se estabeleceu como base, não só para o ensino teórico-prático, mas também na organização de um corpo de enfermagem, que teria voz no hospital psiquiátrico, agora interessado em abandonar suas características asilares, para estar em conformidade com o discurso da nova psiquiatria.

Em 1963, o nome professora Teresa Sena e de suas colaboradoras passam a constar na relação de profissionais integrantes da equipe de saúde do IPUB, em seu órgão de divulgação oficial, o Jornal Brasileiro de Psiquiatria. Essa iniciativa demonstra a valorização da enfermagem agora praticada no Instituto, bem como o reconhecimento acadêmico do trabalho de enfermeiras na instituição. Desta forma, o IPUB validou o êxito do novo modelo de assistência de enfermagem adaptado pela EAN.

\section{CONCLUSÃO}

A colocação de uma professora enfermeira especializada em enfermagem psiquiátrica na chefia de enfermagem do IPUB impulsionou um movimento de construção de saberes e fazeres da enfermagem psiquiátrica, que se reorganizou de forma

\section{Referências}

1. Universidade Federal do Rio de Janeiro. Escola de Enfermagem Anna Nery. Centro de Documentação. Histórico das alunas: 19231950. Rio de Janeiro (RJ): UB/EAN; 1960.

2. Lei $n^{0} 775$, de 06 de agosto de 1949. Dispõe sobre o ensino na enfermagem no país e da outras providências. Diário Oficial da República Federativa do Brasil, Rio de Janeiro (DF), 7 ago 1949.

3. Andrade MDL. Entrevista concedida a Cristina Loyola em 1990 na cidade do Rio de Janeiro.[1 1fita cassete] Rio de Janeiro (RJ): UFRJ EEAN/Centro de Documentação; 1990.

4. Universidade Federal do Rio de Janeiro. Escola de Enfermagem Anna Nery. Centro de Documentação. Ofício n⿳37, de 19 de janeiro de 1960. Trata da substituição de encarregada de curso na disciplina Enfermagem Psiquiátrica. Rio de Janeiro (RJ): UFRJ/EEAN; 1960.

5. Organização Mundial de Saúde-OMS. Relatório do Comitê de Expertos em Enfermeria Psiquiátrica. Primer Informe. Genebra (CH); 1955. Série de Informes Técnicos, 105.

6. Fausto B. História concisa do Brasil. São Paulo (SP): Edusp/ Imprensa Oficial do Estado; 2001.

7. Freitas CM. Contribuição ao problema da assistência psiquiátrica do Estado da Guanabara. J Bras Psiquiatr 1962 jan/mar; 1 (1): 4-21. diferente e positiva. Essa professora direcionou o trabalho da enfermagem para as concepções da "Nova Psiquiatria", as quais o IPUB vinha procurando se apropriar.

A construção de um campo de estágio adequado beneficiou não somente as alunas da EAN, mas também alunas de outras escolas de enfermagem em dificuldades para cumprir as novas exigências legais que tornaram obrigatório o ensino teórico e prático da enfermagem psiquiátrica.

Tais avanços se tornaram possíveis pela presença de uma especialista altamente capacitada na chefia de enfermagem do IPUB, ocupando estrategicamente esse espaço institucional. 0 notável empreendimento de implantação de um novo modelo teórico-prático de assistência e de ensino de enfermagempsiquiátrica teve à frente a figura da professora Teresa de Jesus Sena, que, além de unir a condição de responsável pela disciplina de enfermagem psiquiátrica na EAN à de chefe do serviço de enfermagem do IPUB, usufruía de notável prestígio, tanto junto à direção da EAN quanto à direção do IPUB.

Esta professora soube conduzir de forma brilhante as relações conflituosas com a prática médica e a de enfermagem no IPUB. A evolução e a transformação do discurso teóricoprático da enfermagem psiquiátrica, em decorrência do seu reconhecimento na Universidade do Brasil, culminaram com a difusão desse modelo para outras escolas de enfermagem do Rio de Janeiro e de outros estados.

A partir do reconhecimento do novo modelo de enfermagem psiquiátrica no meio acadêmico/institucional, foi aberto o caminho para a elaboração de um discurso próprio à enfermagem, condição para a busca de uma maior autonomia profissional e essencial ao seu melhor posicionamento na área da psiquiatria.

8. Maia E. Visão panorâmica da assistência psiquiátrica no Brasil. Rev Bras Saude Mental 1961; 6

9. Lopes JL. Higiene mental. J Bras Psiquiatr 1963 jan/mar; 1 (1): 256-76.

10. Ministério da Saúde (BR). Conselho Nacional de Saúde. Diretrizes e normas regulamentadoras de pesquisas envolvendo seres humanos. Resolução CNS n 196, de 10 de outubro de 1996. Inf Epidemiol SUS 1996; 5 (2 supl 3): 13-41.

11. Miranda CML. 0 parentesco imaginário: história e representação social da loucura do espaço asilar. Rio de Janeiro (RJ): Cortez/UFRJ; 1994.

12. Sena TJ. Entrevista concedida a Maria Angélica Peres em 2002 na cidade de Fortaleza.[1 cassete sonoro]. Rio de Janeiro (RJ): UFRJ/ EEAN/Centro de Documentação; 2002.

13. Sena TJ. A enfermagem psiquiátrica na realidade brasileira. Rev Bras Enf 1965 out; 4: 65-71.

14. Sena TJ. Entrevista concedida a Cristina Loyola em 1990 na cidade do Rio de Janeiro.[2 cassetes sonoros]. Rio de Janeiro (RJ): UFRJ/ EEAN/Centro de Documentação; 1990.

15. Foucault M. Microfísica do poder. Rio de Janeiro (RJ): Graal; 2003.

16. Foucault M. Arqueologia do saber. Rio de Janeiro (RJ): Forense Universitária; 2004.

17. Associação Brasileira de Enfermeiras Diplomadas. Resoluções do $3^{\circ}$ Congresso Nacional de Enfermagem. An Enf 1950 jan; 3 (1): 23-27. 
18. Associação Brasileira de Enfermeiras Diplomadas. Resoluções do $4^{\circ}$ Congresso Nacional de Enfermagem. An Enf 1951 jan; 4 (1): 28-32

19. Universidade Federal do Rio de Janeiro. Escola de Enfermagem Anna Nery. Centro de Documentação. Ofício n 284, de 04 de abril de 1962. Comunica ao Diretor do IPUB os serviços prestados pela Enfermeira Teresa de Jesus Sena. Rio de Janeiro (RJ): EEAN/UFRJ; 1962.
20. Minzoni MA. Levantamento do ensino de enfermagem psiquiátrica nas escolas de enfermagem do Brasil. Rev Bras Enf 1966 set/out/ nov/dez; 5-6: 314-21.

21. Universidade Federal do Rio de Janeiro. Escola de Enfermagem Anna Nery. Centro de Documentação. Ofício n¹036, dezembro de 1961. Trata das realizações culturais da EEAN no ano de 1961. Rio de Janeiro (RJ): EEAN/UFRJ; 1961. 